\title{
Cachoeiras como refúgio para briófitas no Cerrado Brasileiro
}

\author{
Waterfalls as a refuge for bryophytes in the Brazilian Cerrado \\ Cascadas como refugio de briófitas en el Cerrado brasileño
}

Recebido: 20/08/2021 | Revisado: 25/08/2021 | Aceito: 29/08/2021 | Publicado: 31/08/2021

\author{
Lúciu Rezende Fernandes \\ ORCID: https://orcid.org/0000-0001-6874-1196 \\ Universidade Estadual do Mato Grosso, Brasil \\ E-mail: luciufernandes@gmail.com \\ Francisco de Paula Athayde-Filho \\ ORCID: https://orcid.org/0000-0002-9514-8176 \\ Universidade Estadual do Mato Grosso, Brasil \\ E-mail: fpafilho@terra.com.br \\ Denilson Fernandes Peralta \\ ORCID: https://orcid.org/0000-0003-4304-7258 \\ Instituto de Pesquisas Ambientais, Brasil \\ E-mail: denilsonfperalta@gmail.com
}

\begin{abstract}
Resumo
Seis cachoeiras foram estudadas, estando três localizadas no município de Mineiros-GO e três no município de Nova Xavantina-MT, todas imersas no Bioma Cerrado, visando analisar a distribuição das espécies de briófitas em ambientes de cachoeiras. Foram encontradas 102 espécies de briófitas (68 gêneros e 37 famílias), e Lejeuneaceae foi a família mais rica (14 espécies). Os ambientes relacionados às cachoeiras amostrados foram "vereda" (montante), cachoeira (queda d' água) e mata de galeria (jusante), diferenciados entre si pela umidade e incidência luminosa. As cachoeiras modificam os ambientes relacionados com o aumento na riqueza e composição de espécies, e mudam a comunidade em relação às formas de vida das espécies colonizadoras. As cachoeiras dos dois municípios apresentaram diferenças florísticas, pois as espécies encontradas nas cachoeiras de Nova Xavantina-MT apresentaram influência do bioma amazônico, enquanto aquelas cachoeiras do município de Mineiros-GO, com o Bioma Pantanal.
\end{abstract}

Palavras-chave: Briófitas; Savana brasileira; Mata de galeria; Vereda; Ecologia de cachoeiras.

\begin{abstract}
Six waterfalls were studied, all in the Cerrado Biome, three located in the county of Mineiros/Goiás state and three in the county of Nova Xavantina/Mato Grosso state in order to analyze the distribution of species in the environments associated with waterfalls. We found 102 bryophytes species (68 genera and 37 families). Lejeuneaceae was the richest one (14 species). The habitats with waterfall influence sampled were "vereda" (upstream), waterfall (fall creek) and gallery forests (downstream), they are differentiated specially by its humidity and shading. The waterfall influences in the habitats related show increase in richness and composition, and change the community in relation to the life forms of the colonists species. The waterfalls of the two counties have floristic differences in composition, with the waterfalls of Nova Xavantina show influence of the Amazon Biome and Mineiros with Pantanal biome.
\end{abstract}

Keywords: Bryophytes; Brazilian savanna; Gallery forest; Vereda; Waterfall ecology.

\section{Resumen}

Se estudiaron seis cascadas, todas en el Bioma Cerrado, tres ubicadas en el municipio de Mineiros/estado de Goiás y tres en el municipio de Nova Xavantina/estado de Mato Grosso, con el objetivo de analizar la distribución de especies de briofitas en ambientes de cascadas. Se encontraron 102 especies de briófitas (68 géneros y 37 familias) y Lejeuneaceae fue la familia más rica (14 especies). Los ambientes relacionados con las cascadas muestreadas fueron "vereda" (río arriba), cascada (cascada) y bosque de galería (río abajo), estos ambientes se diferencian por humedad y sombra. Las cascadas modifican los ambientes relacionados con el aumento de riqueza y composición, y cambian la comunidad en relación a las formas de vida de las especies colonizadoras. Las cascadas de los dos municipios mostraron diferencias florísticas, ya que las especies encontradas en las cascadas de Nova Xavantina fueron influenciadas por el Bioma Amazónico y las cascadas en el municipio de Mineiros con el Bioma Pantanal.

Palabras clave: Briófitas; Sabana brasileña; Bosque de galería; Sendero; Ecología de cascadas.

\section{Introdução}

Segundo Lima e Silva (2008), o Cerrado é o segundo maior bioma do Brasil, com cerca de 200 milhões de ha (Aquino \& Aguiar 2007), ocupando aproximadamente $24 \%$ do território nacional. A região do Cerrado abrange os estados de Goiás, 
Tocantins e Distrito Federal e parte dos estados da Bahia, Ceará, Maranhão, Mato Grosso, Mato Grosso do Sul, Minas Gerais, Piauí, Rondônia e São Paulo, além de ocorrer de forma disjunta em áreas nos estados do Amapá, Amazonas, Pará, Paraná e Roraima (Ribeiro \& Walter 2008).

Existem onze tipos de subdivisões para a vegetação conhecida como Cerrado "sensu latu", com ênfase especial para os tipos de savana e áreas com afloramento rochoso ou corpos de água (Ribeiro \& Walter 2008). As veredas são um tipo de vegetação vegetal savânica com alta frequência da palmeira Mauritia flexuosa L.f. (Buriti) emergindo entre aglomerados de espécies arbustivas densas e herbáceas, ocorrendo próximo a nascentes ou bordas de matas de galeria. As matas de galeria são formações vegetais florestais que ocorrem ao longo de pequenos rios e riachos, formando corredores fechados (galerias) sobre a água (Ribeiro et al. 2001, Ribeiro \& Walter 2008). Ambas fitofisionomias, por suas características estruturais, detêm elevada umidade, com níveis variáveis de sombreamento, uma vez que nas matas de galeria observa-se a formação de dossel, enquanto nas veredas, de maneira geral, há elevada incidência solar. Essas características acabam por favorecer a ocorrência de uma elevada diversidade de espécies de briófitas.

No Brasil existem cerca de 1.610 espécies de briófitas, distribuídas em 409 gêneros e 117 famílias (Flora do Brasil 2020). Na região Centro-Oeste do Brasil, a flora de briófitas permanece pouco conhecida e 511 espécies são registradas (Câmara et al. 2003, Yano \& Bastos 2004; Câmara \& Vital 2004; Câmara et al. 2005; Câmara \& Costa, 2006; Genevro et al. 2006; Oliveira et al. 2006; Câmara 2008; Câmara \& Soares 2010; Sousa et al. 2010, Flora do Brasil 2020). Destes, 311 são registrados para o estado de Mato Grosso e 340 para Goiás (Flora do Brasil 2020).

As briófitas colonizam uma grande variedade de substratos e habitats, incluindo solos perturbados ao longo das margens de riachos, trilhas e estradas (Crandall-Stotler et al. 2009), paredes, troncos de árvores vivos e mortos, folhas e cupins (Yano 1984), e rochas à beira de riachos e cachoeiras (Brito \& Pôrto 2000). Normalmente os trabalhos realizados com levantamento de briófitas trazem informações sobre colonização de substratos, porém são raros os que localizam as espécies dentro das áreas estudadas, categorizando em relação a áreas florestadas, campos, matas de galerias, entre outros

O estudo de plantas em ambientes associados a cachoeiras é escasso e apenas três artigos foram encontrados na literatura e, destes, apenas um incluiu briófitas. Pinto e Oliveira-Filho (1999) estudaram a comunidade de angiospermas no vale da cachoeira Véu da Noiva na Chapada dos Guimarães, Brasil; Oliveira Filho e Martins (1986) analisaram a flora associada a riachos e cachoeiras da região da Salgadeira próximo à Chapada dos Guimarães, Brasil, e de Djan-Chekar (1993), trabalhando em sua tese de doutorado com briófitas associadas a cachoeira na Colúmbia Britânica, Canadá.

As cachoeiras e os ambientes associados como mata de galeria e veredas contribuem para a permanência de espécies sensíveis à dessecação, especialmente as briófitas que são poiquiloídricas. No Bioma Cerrado as chuvas são sazonais e restritas ao verão, e assim os ambientes que mantêm a umidade mesmo durante o ano todo funcionam como refúgios para muitas as espécies.

Este estudo tem como objetivo avaliar e comparar a composição florística e analisar o comportamento ecológico de briófitas que ocorrem em ambientes associados a cachoeiras, na região do Cerrado em Goiás e Mato Grosso. Descrevendo assim como esses ambientes possibilitam a permanência de espécies sensíveis à dessecação como as briófitas.

\section{Metodologia}

Foram estudadas seis cachoeiras com características semelhantes (geomorfologicamente e flora circundante), todas dentro do Bioma Cerrado, na região Centro-Oeste do Brasil e clima Aw, segundo Köeppen (Silva et al. 2008). A altura das quedas é de aproximadamente $10 \mathrm{~m}$ (mais alta com $14 \mathrm{~m}$ e mais baixa $6 \mathrm{~m}$ ). Três estão localizadas no município de MineirosGO, enquanto outras três no município de Nova Xavantina-MT (Quadro 1, Figura 1). 
Quadro 1. Caracterização das três cachoeiras estudadas no município de Mineiros estado de Goiás (MIGO) e três no município de Nova Xavantina estado do Mato Grosso (NOMT).

\begin{tabular}{|c|c|c|c|c|c|}
\hline $\begin{array}{l}\text { Nome da } \\
\text { Cachoeira }\end{array}$ & $\begin{array}{l}\text { Altura de } \\
\text { queda } \\
\text { (metros) }\end{array}$ & Rio Acima (montante) & Cachoeira & Rio Abaixo (jusante) & Coordenadas \\
\hline $\begin{array}{l}\text { Adão/MT } \\
\text { (AdMT) }\end{array}$ & 12 & $\begin{array}{l}\text { "Vereda", sem presença } \\
\text { de mata ciliar nas } \\
\text { margens do riacho, e } \\
\text { estão bem preservadas, } \\
\text { sem sinais de } \\
\text { perturbação humana }\end{array}$ & $\begin{array}{l}\text { mata de galeria é } \\
\text { fechada, mas menos } \\
\text { densa, pois há muitas } \\
\text { rochas ao longo do } \\
\text { trecho }\end{array}$ & $\begin{array}{l}\text { floresta está bem } \\
\text { preservada sem } \\
\text { nenhum sinal de ação } \\
\text { humana }\end{array}$ & $\begin{array}{l}14^{\circ} 48^{\prime} 21.1^{\prime \prime} \mathrm{S} \\
- \\
52^{\circ} 30^{\prime} 08.3^{\prime}, \mathrm{W}\end{array}$ \\
\hline $\begin{array}{l}\text { Chupador/ } \\
\text { MT } \\
\text { (ChMT) }\end{array}$ & 8 & $\begin{array}{l}\text { "Vereda", mostrando } \\
\text { sinais de interferência } \\
\text { humana como a cerca de } \\
\text { arame e pegadas de gado } \\
\text { no solo, mas a vegetação } \\
\text { não mudou muito }\end{array}$ & $\begin{array}{l}\text { mata de galeria é } \\
\text { fechada, mas menos } \\
\text { densa, pois há muitas } \\
\text { rochas ao longo do } \\
\text { trecho }\end{array}$ & $\begin{array}{l}\text { bom estado após este } \\
\text { trecho existem alguns } \\
\text { locais abertos devido } \\
\text { ao acesso de gado e } \\
\text { também alguns } \\
\text { trechos onde a mata } \\
\text { de galeria é mais } \\
\text { estreita e algumas } \\
\text { erosões }\end{array}$ & $\begin{array}{l}14^{\circ} 50^{\prime} 08.7^{\prime} \mathrm{S} \\
- \\
52^{\circ} 30^{\prime} 03.7^{\prime}, \mathrm{W}\end{array}$ \\
\hline $\begin{array}{l}\text { Botina/MT } \\
\text { (BoMT) }\end{array}$ & 10 & $\begin{array}{l}\text { "Vereda", sem presença } \\
\text { de mata ciliar, em bom } \\
\text { estado, sem sinais de } \\
\text { mudanças no ambiente e } \\
\text { em manchas de cerrado } \\
\text { rupestre }\end{array}$ & $\begin{array}{l}\text { bem conservada e } \\
\text { devido à alta umidade, a } \\
\text { parede é formada por } \\
\text { esteiras de vegetação } \\
\text { briófitas, samambaias e } \\
\text { outras plantas }\end{array}$ & $\begin{array}{l}\text { bem preservada, a } \\
\text { maior parte da mata } \\
\text { de galeria está } \\
\text { próxima à presença de } \\
\text { pastagens e manchas } \\
\text { de vereda. }\end{array}$ & $\begin{array}{l}14^{\circ} 45^{\prime} 02.2^{\prime} ’ \mathrm{~S} \\
- \\
52^{\circ} 33^{\prime} 12.5^{\prime}, \mathrm{W}\end{array}$ \\
\hline $\begin{array}{l}\text { Sucuri/GO } \\
\text { (SuGO) }\end{array}$ & 14 & $\begin{array}{l}\text { a floresta é conservada, } \\
\text { mas acima deste ponto } \\
\text { existe um local aberto } \\
\text { com visitação frequente } \\
\text { de turistas }\end{array}$ & $\begin{array}{l}\text { bem conservado, com a } \\
\text { presença de um "tapete } \\
\text { vivo" formado por } \\
\text { briófitas e também } \\
\text { algumas samambaias e } \\
\text { licófitas. }\end{array}$ & $\begin{array}{l}\text { bem preservado, } \\
\text { constituído por mata } \\
\text { ciliar mais fechada }\end{array}$ & $\begin{array}{l}17^{\circ} 32^{\prime} 02.55^{\prime \prime} \mathrm{S} \\
- \\
52^{\circ} 39^{\prime} 50.73 ” \\
\mathrm{~W}\end{array}$ \\
\hline $\begin{array}{l}\text { Pinguela/G } \\
\mathrm{O}(\mathrm{PiGO})\end{array}$ & 10 & $\begin{array}{l}\text { floresta está bastante } \\
\text { alterada, além da } \\
\text { frequente visita de } \\
\text { turistas por lá, também } \\
\text { está pastando nas duas } \\
\text { margens do riacho }\end{array}$ & $\begin{array}{l}\text { A Floresta da Galeria } \\
\text { está fechada, mas a } \\
\text { cachoeira próxima é } \\
\text { uma área limpa porque } \\
\text { o poder da água }\end{array}$ & $\begin{array}{l}\text { bem conservado, } \\
\text { formado por um } \\
\text { grande e bem mata } \\
\text { mais completo }\end{array}$ & $\begin{array}{l}10^{\circ} 32^{\prime} 32.27^{\prime \prime} \mathrm{S} \\
- \\
52^{\circ} 40^{\prime} 00.27^{\prime \prime} \\
\mathrm{W}\end{array}$ \\
\hline $\begin{array}{l}\text { Luzimar/G } \\
\text { O (LuGO) }\end{array}$ & 8 & $\begin{array}{l}\text { floresta de galeria do } \\
\text { outono está bem } \\
\text { conservada }\end{array}$ & $\begin{array}{l}\text { bem conservado, com a } \\
\text { presença de um "tapete } \\
\text { vivo" formado por } \\
\text { briófitas forro da gota e } \\
\text { também algumas } \\
\text { samambaias e licófitas. }\end{array}$ & $\begin{array}{l}\text { alterada pela presença } \\
\text { de pastagem nas duas } \\
\text { margens do riacho, há } \\
\text { apenas uma estreita } \\
\text { faixa de mata de } \\
\text { galeria, onde a } \\
\text { cobertura de dossel } \\
\text { em ambos os lados } \\
\text { não fica na maior } \\
\text { parte do caminho. }\end{array}$ & $\begin{array}{l}17^{\circ} 37^{\prime} 24.89^{\prime \prime} \mathrm{S} \\
- \\
52^{\circ} 35^{\prime} 34.13 \prime \prime \\
\mathrm{W}\end{array}$ \\
\hline
\end{tabular}

Fonte: Autores. 
Figura 1. Localização das seis cachoeiras estudadas nos municípios de Mineiros no estado de Goiás (MIGO): Su - Sucuri, pertencente ao Rio Verde (foto do ambiente por Patricia Fetter); Pi - Pinguela, formada pelo córrego Ribeirão (foto do ambiente por Luciu Fernandes); Lu - Luzimar advinda do córrego Mané Joaquim (foto do ambiente por Luciu Fernandes); e Nova Xavantina no estado do Mato Grosso (NOMT): Bo - Botina (foto do ambiente por Luciu Fernandes); Ad - Adão (foto do ambiente por Sergio Lopes de Oliveira); Ch - Chupador (foto do ambiente por Luciu Fernandes).

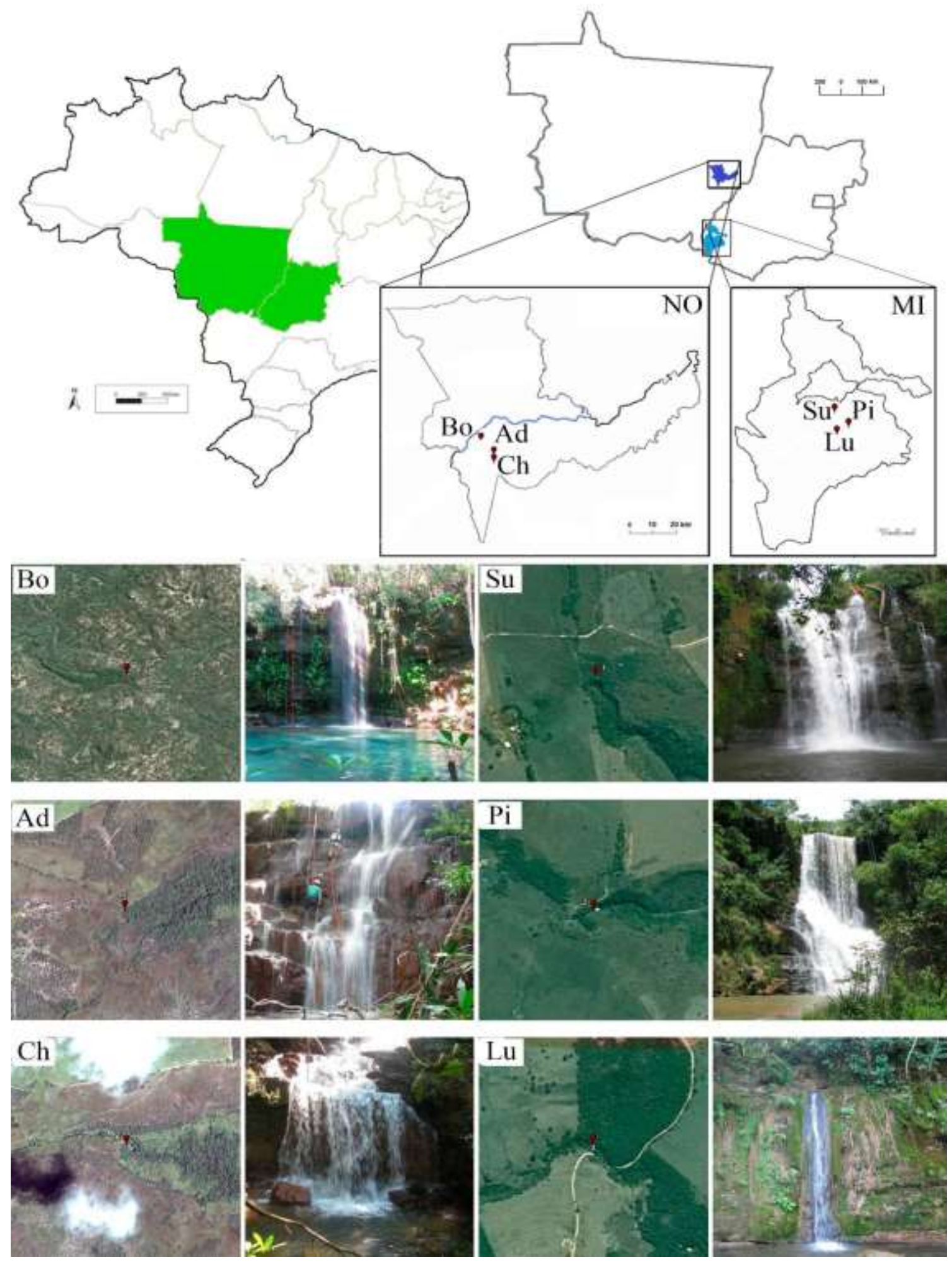

Fonte: Mapas do Instituto Brasileiro de Geografia e Estatística (IBGE); Imagens de satélite do programa Google Earth 6.0.2, modificadas por Lúciu Rezende Fernandes. 
A amostragem das briófitas foi realizada de forma qualitativa, onde as espécies foram coletadas a montante, ao longo da queda e a jusante das cachoeiras, considerando, para tanto, um segmento de $500 \mathrm{~m}$ a montante e outro a jusante da queda. Dentro dessa área, foi considerada uma faixa de $10 \mathrm{~m}$ à partir do leito do córrego, em direção ao interior da floresta, em ambos os lados. Para avaliar a distribuição das briófitas ao longo da queda de água da cachoeira foram analisados extratos de $2 \mathrm{~m}$ de altura, do início ao final da queda.

As coletas de amostras seguem Frahm (2003) e o sistema de classificação de Crandall-Stotler et al. (2009) para Marchantiophyta e Goffinet et al. (2009) para Bryophyta. Os nomes foram checados e atualizados de acordo com W3TROPICOS (2011) e a lista de espécies da Flora do Brasil (Flora do Brasil 2020). Os espécimes são depositados no Herbarium NX, com duplicatas no ICN, PACA, SJRP e SP (siglas de acordo com Holmgren et al. 1990).

Para as análises ecológicas, foram consideradas algumas padronizações apresentadas a seguir. Quanto ao Ambiente Preferencial, as briófitas amostradas foram classificadas em: plantas coletadas a montante (mo) da cachoeira; plantas coletadas na queda de água (qu) e; plantas coletadas a jusante (ju) da cachoeira. Quanto à Distribuição pelos Biomas segue a disponível no Flora do Brasil (2020): AM - Amazônia, CA - Caatinga, CE - Cerrado, MA - Mata Atlântica, PA - Pampa, PT - Pantanal. No que se refere às formas de vida foram classificadas segundo Austrheim et al. (2005) subdividindo hepáticas em talosas e folhosas: acr - Acrocárpico, ple - pleurocárpico, hta - hepática talosa, hfo - hepática folhosa, sph - Sphagnum.

A similaridade florística foi analisada usando o Índice de Jaccard (Durigan 2003), e dendrogramas construídos com o programa BioDiversity Professional, versão 2.

\section{Resultados e Discussão}

Este levantamento registrou 102 espécies de briófitas, distribuídas em 68 gêneros e 37 famílias (Quadro 2). A família mais representativa foi Lejeuneaceae com 14 espécies (13\% do total), seguida por nove espécies Fissidentaceae (8\%) e oito espécies de Sematophyllaceae (7\%) (Figura 2). Observou-se também que 17 famílias tiveram uma espécie cada (1\% do total). 


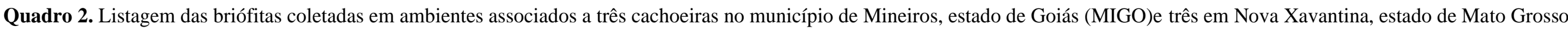

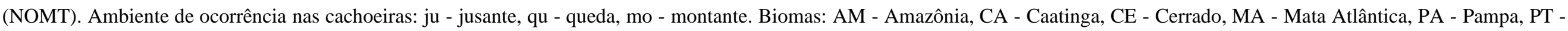

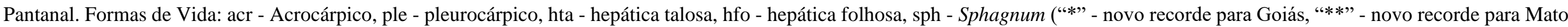
Grosso).

\begin{tabular}{|c|c|c|c|c|c|c|c|c|c|c|c|c|c|c|c|c|c|c|c|c|c|c|c|c|c|c|c|c|c|}
\hline \multirow[b]{2}{*}{ Espécies } & \multicolumn{3}{|c|}{$\begin{array}{l}\text { MIGO } \\
\text { Lu }\end{array}$} & \multicolumn{3}{|c|}{$\begin{array}{l}\text { MIGO } \\
\text { Pi }\end{array}$} & \multicolumn{3}{|c|}{$\begin{array}{l}\text { MIGO } \\
\text { Su }\end{array}$} & \multicolumn{3}{|c|}{$\begin{array}{l}\text { NOMT } \\
\text { Bo }\end{array}$} & \multicolumn{3}{|c|}{$\begin{array}{l}\text { NOMT } \\
\text { Ch }\end{array}$} & \multicolumn{3}{|c|}{$\begin{array}{l}\text { NOMT } \\
\text { Ad }\end{array}$} & \multirow[b]{2}{*}{ Freq. } & \multicolumn{3}{|c|}{$\begin{array}{l}\text { Ambiente de } \\
\text { ocorrência }\end{array}$} & \multicolumn{6}{|c|}{ Biomas } & \multirow{2}{*}{$\begin{array}{l}\text { Forma } \\
\text { de } \\
\text { Vida }\end{array}$} \\
\hline & mo & qu & ju & mo & qu & ju & mo & qu & ju & mo & qu & ju & mo & qu & ju & mo & qu & ju & & mo & qu & ju & $\begin{array}{l}\mathbf{A} \\
\mathbf{M}\end{array}$ & $\begin{array}{l}\mathbf{C} \\
\mathbf{A}\end{array}$ & $\mathbf{C E}$ & $\begin{array}{l}\mathbf{M} \\
\mathbf{A}\end{array}$ & PA & PT & \\
\hline $\begin{array}{l}\text { Riccardia cataractarum (Spruce) } \\
\text { Schiffn. }\end{array}$ & 0 & 0 & 0 & 0 & 1 & 1 & 0 & 1 & 1 & 0 & 1 & 1 & 1 & 1 & 0 & 0 & 1 & 0 & 0,50 & 1 & 1 & 1 & 0 & 0 & 1 & 1 & 0 & 1 & hta \\
\hline Jaegerina scariosa (Lorentz) Arzeni & 1 & 0 & 1 & 1 & 0 & 1 & 1 & 1 & 1 & 0 & 0 & 0 & 0 & 0 & 1 & 0 & 0 & 1 & 0,44 & 1 & 1 & 1 & 1 & 0 & 1 & 1 & 0 & 1 & ple \\
\hline $\begin{array}{l}\text { Microcalpe subsimplex (Hedw.) W.R. } \\
\text { Buck }\end{array}$ & 0 & 0 & 0 & 0 & 0 & 1 & 0 & 1 & 1 & 1 & 1 & 1 & 1 & 0 & 1 & 0 & 0 & 1 & 0,44 & 1 & 1 & 1 & 1 & 1 & 1 & 1 & 1 & 1 & ple \\
\hline $\begin{array}{l}\text { Chryso-hypnum diminutivum (Hampe) } \\
\text { W.R.Buck }\end{array}$ & 1 & 0 & 1 & 1 & 0 & 1 & 1 & 0 & 0 & 0 & 0 & 1 & 0 & 0 & 1 & 0 & 0 & 1 & 0,39 & 1 & 0 & 1 & 1 & 0 & 1 & 1 & 1 & 1 & ple \\
\hline $\begin{array}{l}\text { Pteropsiella metzgeriiformis R.M. } \\
\text { Schust. ** }\end{array}$ & 0 & 0 & 0 & 0 & 0 & 0 & 0 & 0 & 0 & 1 & 1 & 1 & 1 & 1 & 1 & 0 & 1 & 0 & 0,39 & 1 & 1 & 1 & 1 & 0 & 0 & 1 & 0 & 0 & hfo \\
\hline $\begin{array}{l}\text { Cheilolejeunea rigidula (Mont.) R.M. } \\
\text { Schust. }\end{array}$ & 1 & 0 & 1 & 0 & 0 & 1 & 1 & 0 & 0 & 0 & 0 & 0 & 0 & 1 & 1 & 0 & 0 & 1 & 0,33 & 1 & 1 & 1 & 1 & 1 & 1 & 1 & 0 & 1 & hfo \\
\hline $\begin{array}{l}\text { Ochrobryum gardneri (Müll.Hal.) } \\
\text { Lindb. }\end{array}$ & 0 & 0 & 0 & 0 & 0 & 1 & 0 & 0 & 0 & 1 & 1 & 1 & 0 & 1 & 1 & 0 & 0 & 1 & 0,33 & 1 & 1 & 1 & 1 & 0 & 1 & 1 & 0 & 1 & acr \\
\hline $\begin{array}{l}\text { Zoopsidella integrifolia (Spruce) } \\
\text { R.M.Schust. }\end{array}$ & 0 & 0 & 0 & 0 & 0 & 0 & 0 & 0 & 0 & 1 & 1 & 1 & 1 & 1 & 0 & 0 & 1 & 0 & 0,33 & 1 & 1 & 1 & 1 & 0 & 1 & 1 & 0 & 0 & hfo \\
\hline $\begin{array}{l}\text { Brittonodoxa subpinnata (Brid.) W.R. } \\
\text { Buck, P.E.A.S.Câmara \& Carv.-Silva }\end{array}$ & 0 & 0 & 1 & 0 & 1 & 1 & 0 & 1 & 1 & 0 & 0 & 0 & 0 & 0 & 0 & 0 & 0 & 1 & 0,28 & 0 & 1 & 1 & 1 & 0 & 1 & 1 & 0 & 0 & ple \\
\hline $\begin{array}{l}\text { Fossombronia porphyrorhiza (Nees) } \\
\text { Prosk. }\end{array}$ & 0 & 1 & 0 & 0 & 1 & 1 & 0 & 1 & 1 & 0 & 0 & 0 & 0 & 0 & 0 & 0 & 0 & 1 & 1 & 1 & 1 & 1 & 0 & 1 & 1 & 1 & 0 & 1 & hfo \\
\hline
\end{tabular}


Research, Society and Development, v. 10, n. 11, e272101119647, 2021

(CC BY 4.0) | ISSN 2525-3409 | DOI: http://dx.doi.org/10.33448/rsd-v10i11.19647

\begin{tabular}{|c|c|c|c|c|c|c|c|c|c|c|c|c|c|c|c|c|c|c|c|c|c|c|c|c|c|c|c|c|c|}
\hline Barbula arcuata Griff. & 1 & 1 & 1 & 0 & 0 & 0 & 0 & 1 & 1 & 0 & 0 & 0 & 0 & 0 & 0 & 0 & 0 & 0 & 0,28 & 1 & 1 & 1 & 1 & 0 & 1 & 1 & 0 & 0 & acr \\
\hline Bryum limbatum Müll.Hal. * & 0 & 0 & 1 & 0 & 1 & 1 & 0 & 1 & 1 & 0 & 0 & 0 & 0 & 0 & 0 & 0 & 0 & 0 & 0,28 & 0 & 1 & 1 & 0 & 0 & 1 & 1 & 0 & 0 & acr \\
\hline Lejeunea laetevirens Nees \& Mont. & 1 & 0 & 1 & 1 & 0 & 0 & 0 & 0 & 1 & 0 & 0 & 0 & 0 & 0 & 1 & 0 & 0 & 0 & 0,28 & 1 & 0 & 1 & 1 & 1 & 1 & 1 & 0 & 1 & hfo \\
\hline $\begin{array}{l}\text { Philonotis sphaerocarpa (Hedw.) } \\
\text { Brid. * }\end{array}$ & 0 & 1 & 1 & 1 & 1 & 0 & 0 & 1 & 0 & 0 & 0 & 0 & 0 & 0 & 0 & 0 & 0 & 0 & 0,28 & 1 & 1 & 1 & 1 & 1 & 1 & 1 & 0 & 0 & acr \\
\hline $\begin{array}{l}\text { Micropterygium pterygophyllum } \\
\text { (Nees) Trevis. }\end{array}$ & 0 & 0 & 0 & 0 & 0 & 0 & 0 & 0 & 0 & 1 & 1 & 1 & 0 & 0 & 1 & 0 & 0 & 1 & 0,22 & 1 & 1 & 1 & 1 & 0 & 1 & 1 & 0 & 0 & hfo \\
\hline $\begin{array}{l}\text { Chionoloma schlimii (Müll.Hal.) M. } \\
\text { Alonso et al. }\end{array}$ & 1 & 1 & 0 & 1 & 1 & 0 & 0 & 0 & 0 & 0 & 0 & 0 & 0 & 0 & 0 & 0 & 0 & 0 & 0,22 & 1 & 1 & 0 & 0 & 0 & 1 & 1 & 0 & 1 & acr \\
\hline Hyophilla involuta (Hook.) A. Jaeger & 1 & 1 & 1 & 0 & 0 & 0 & 1 & 0 & 0 & 0 & 0 & 0 & 0 & 0 & 0 & 0 & 0 & 0 & 0,22 & 1 & 1 & 1 & 1 & 0 & 1 & 1 & 1 & 1 & acr \\
\hline Pallavicinia lyellii (Hook.) S.F. Gray & 0 & 0 & 0 & 0 & 0 & 0 & 0 & 0 & 0 & 1 & 1 & 0 & 0 & 1 & 0 & 0 & 1 & 0 & 0,22 & 1 & 1 & 0 & 1 & 0 & 1 & 1 & 0 & 1 & hta \\
\hline Philonotis uncinata (Schwägr.) Brid. & 1 & 1 & 0 & 0 & 1 & 1 & 0 & 0 & 0 & 0 & 0 & 0 & 0 & 0 & 0 & 0 & 0 & 0 & 0,22 & 1 & 1 & 1 & 1 & 1 & 1 & 1 & 1 & 1 & acr \\
\hline $\begin{array}{l}\text { Vesicularia vesicularis (Schwägr.) } \\
\text { Broth. }\end{array}$ & 1 & 1 & 1 & 0 & 1 & 0 & 0 & 0 & 0 & 0 & 0 & 0 & 0 & 0 & 0 & 0 & 0 & 0 & 0,22 & 1 & 1 & 1 & 1 & 0 & 1 & 1 & 0 & 1 & ple \\
\hline Isopterygium tenerum (Sw.) Mitt. & 1 & 0 & 0 & 0 & 0 & 1 & 0 & 0 & 0 & 0 & 0 & 0 & 0 & 1 & 0 & 0 & 0 & 1 & 0,17 & 1 & 1 & 1 & 1 & 1 & 1 & 1 & 1 & 1 & ple \\
\hline Octoblepharum albidum Hedw. & 0 & 0 & 0 & 1 & 0 & 0 & 1 & 0 & 0 & 0 & 0 & 0 & 0 & 0 & 1 & 0 & 0 & 1 & 0,17 & 1 & 0 & 1 & 1 & 1 & 1 & 1 & 1 & 1 & acr \\
\hline $\begin{array}{l}\text { Thuidium tomentosum Schimp. ex } \\
\text { Besch. }\end{array}$ & 1 & 0 & 0 & 1 & 0 & 1 & 0 & 0 & 0 & 0 & 0 & 0 & 0 & 0 & 0 & 0 & 0 & 1 & 0,17 & 1 & 0 & 1 & 1 & 0 & 1 & 1 & 1 & 0 & ple \\
\hline $\begin{array}{l}\text { Vitalia galipensis (Müll. Hal.) } \\
\text { P.E.A.S.Câmara, Carv.-Silva \& W.R. } \\
\text { Buck }\end{array}$ & 0 & 0 & 0 & 0 & 0 & 1 & 0 & 1 & 0 & 0 & 0 & 0 & 0 & 0 & 1 & 0 & 0 & 1 & 0,17 & 0 & 1 & 1 & 1 & 0 & 1 & 1 & 0 & 0 & ple \\
\hline $\begin{array}{l}\text { Brittonodoxa lithophila (Hornsch.) } \\
\text { W.R. Buck, P.E.A.S.Câmara \& Carv.- } \\
\text { Silva * }\end{array}$ & 0 & 0 & 0 & 0 & 1 & 0 & 0 & 1 & 1 & 0 & 0 & 0 & 0 & 0 & 0 & 0 & 0 & 0 & 0,17 & 0 & 1 & 1 & 0 & 0 & 0 & 1 & 0 & 0 & ple \\
\hline $\begin{array}{l}\text { Callicostella pallida (Hornsch.) } \\
\text { Angstr. }\end{array}$ & 0 & 0 & 0 & 0 & 0 & 0 & 0 & 0 & 0 & 0 & 0 & 1 & 0 & 1 & 1 & 0 & 0 & 0 & 0,17 & 0 & 1 & 1 & 1 & 1 & 1 & 1 & 1 & 1 & ple \\
\hline
\end{tabular}


Research, Society and Development, v. 10, n. 11, e272101119647, 2021

(CC BY 4.0) | ISSN 2525-3409 | DOI: http://dx.doi.org/10.33448/rsd-v10i11.19647

\begin{tabular}{|c|c|c|c|c|c|c|c|c|c|c|c|c|c|c|c|c|c|c|c|c|c|c|c|c|c|c|c|c|c|}
\hline $\begin{array}{l}\text { Chionoloma tenuirostre (Hook. \& } \\
\text { Taylor) M. Alonso, M.J. Cano \& J.A. } \\
\text { Jimenez }\end{array}$ & 0 & 0 & 1 & 1 & 1 & 0 & 0 & 0 & 0 & 0 & 0 & 0 & 0 & 0 & 0 & 0 & 0 & 0 & 0,17 & 1 & 1 & 1 & 1 & 1 & 1 & 1 & 0 & 0 & acr \\
\hline $\begin{array}{l}\text { Lejeunea laeta (Lehm. \& Lindenb.) } \\
\text { Gottsche } * * *\end{array}$ & 0 & 1 & 1 & 0 & 0 & 0 & 0 & 0 & 0 & 0 & 0 & 0 & 0 & 1 & 0 & 0 & 0 & 0 & 0,17 & 0 & 1 & 1 & 0 & 0 & 0 & 1 & 0 & 0 & hfo \\
\hline $\begin{array}{l}\text { Macromitrium swainsonii (Hook.) } \\
\text { Brid. }\end{array}$ & 0 & 0 & 0 & 1 & 0 & 0 & 0 & 0 & 0 & 1 & 0 & 0 & 1 & 0 & 0 & 0 & 0 & 0 & 0,17 & 1 & 0 & 0 & 0 & 0 & 1 & 1 & 0 & 0 & ple \\
\hline Symphyogyna brongniartii Mont. * & 1 & 1 & 1 & 0 & 0 & 0 & 0 & 0 & 0 & 0 & 0 & 0 & 0 & 0 & 0 & 0 & 0 & 0 & 0,17 & 1 & 1 & 1 & 1 & 0 & 1 & 1 & 0 & 0 & hta \\
\hline $\begin{array}{l}\text { Campylopus heterostachys (Hampe) } \\
\text { A.Jaeger }\end{array}$ & 0 & 0 & 0 & 0 & 0 & 0 & 0 & 0 & 0 & 0 & 0 & 1 & 0 & 0 & 1 & 0 & 0 & 1 & 0,11 & 0 & 0 & 1 & 1 & 1 & 1 & 1 & 0 & 0 & acr \\
\hline $\begin{array}{l}\text { Ceratolejeunea cornuta (Lindenb.) } \\
\text { Schiffn. ** }\end{array}$ & 0 & 0 & 0 & 0 & 0 & 0 & 0 & 0 & 0 & 0 & 0 & 1 & 0 & 0 & 1 & 0 & 0 & 1 & 0,11 & 0 & 0 & 1 & 1 & 0 & 0 & 1 & 0 & 0 & hfo \\
\hline Fissidens pallidinervis Mitt. & 1 & 0 & 0 & 0 & 0 & 0 & 0 & 0 & 1 & 0 & 0 & 0 & 0 & 0 & 0 & 0 & 0 & 1 & 0,11 & 1 & 0 & 1 & 1 & 1 & 1 & 1 & 0 & 1 & acr \\
\hline Leucobryum laevifolium Broth. ** & 0 & 0 & 0 & 0 & 0 & 0 & 0 & 0 & 1 & 0 & 0 & 1 & 0 & 0 & 0 & 0 & 0 & 1 & 0,11 & 0 & 0 & 1 & 1 & 0 & 0 & 0 & 0 & 0 & acr \\
\hline Lophocolea lindmannii Stephani & 0 & 1 & 0 & 1 & 0 & 0 & 0 & 0 & 0 & 0 & 0 & 0 & 0 & 0 & 0 & 0 & 0 & 1 & 0,11 & 1 & 1 & 1 & 0 & 0 & 1 & 1 & 0 & 0 & hfo \\
\hline Plagiochila martiana (Nees) Lindenb. & 1 & 0 & 0 & 0 & 0 & 0 & 0 & 0 & 1 & 0 & 0 & 0 & 0 & 0 & 0 & 0 & 0 & 1 & 0,11 & 1 & 0 & 1 & 1 & 0 & 1 & 1 & 0 & 1 & hfo \\
\hline Entodon jamesonii (Taylor) Mitt. & 1 & 0 & 1 & 0 & 0 & 0 & 0 & 0 & 0 & 0 & 0 & 0 & 0 & 0 & 0 & 0 & 0 & 0 & 0,11 & 1 & 0 & 1 & 0 & 0 & 1 & 1 & 0 & 0 & ple \\
\hline Fissidens lindbergii Mitt. & 1 & 0 & 0 & 0 & 1 & 0 & 0 & 0 & 0 & 0 & 0 & 0 & 0 & 0 & 0 & 0 & 0 & 0 & 0,11 & 1 & 1 & 0 & 0 & 1 & 1 & 1 & 0 & 0 & acr \\
\hline $\begin{array}{l}\text { Henicodium geniculatum (Mitt.) W.R. } \\
\text { Buck }\end{array}$ & 1 & 0 & 1 & 0 & 0 & 0 & 0 & 0 & 0 & 0 & 0 & 0 & 0 & 0 & 0 & 0 & 0 & 0 & 0,11 & 1 & 0 & 1 & 1 & 0 & 1 & 1 & 0 & 1 & ple \\
\hline Jungermannia hyalina Lyell * & 0 & 0 & 0 & 0 & 0 & 0 & 0 & 1 & 1 & 0 & 0 & 0 & 0 & 0 & 0 & 0 & 0 & 0 & 0,11 & 0 & 1 & 1 & 0 & 0 & 1 & 1 & 0 & 1 & hfo \\
\hline Lejeunea flava (Sw.) Nees & 0 & 0 & 0 & 1 & 0 & 0 & 0 & 0 & 0 & 0 & 0 & 0 & 0 & 0 & 1 & 0 & 0 & 0 & 0,11 & 1 & 0 & 1 & 1 & 1 & 1 & 1 & 1 & 1 & hfo \\
\hline Marchantia papillata Raddi * & 0 & 1 & 1 & 0 & 0 & 0 & 0 & 0 & 0 & 0 & 0 & 0 & 0 & 0 & 0 & 0 & 0 & 0 & 0,11 & 0 & 1 & 1 & 1 & 0 & 1 & 1 & 0 & 1 & hta \\
\hline
\end{tabular}


Research, Society and Development, v. 10, n. 11, e272101119647, 2021

(CC BY 4.0) | ISSN 2525-3409 | DOI: http://dx.doi.org/10.33448/rsd-v10i11.19647

\begin{tabular}{|c|c|c|c|c|c|c|c|c|c|c|c|c|c|c|c|c|c|c|c|c|c|c|c|c|c|c|c|c|c|}
\hline $\begin{array}{l}\text { Thysananthus auriculatus (Wilson \& } \\
\text { Hook) Sukkharak \& Gradst. }\end{array}$ & 0 & 0 & 1 & 0 & 0 & 1 & 0 & 0 & 0 & 0 & 0 & 0 & 0 & 0 & 0 & 0 & 0 & 0 & 0,11 & 0 & 0 & 1 & 0 & 0 & 0 & 1 & 0 & 0 & hfo \\
\hline $\begin{array}{l}\text { Metalejeunea cucullata (Reinw. et al.) } \\
\text { Grolle ** }\end{array}$ & 0 & 0 & 0 & 0 & 0 & 0 & 0 & 0 & 0 & 1 & 0 & 1 & 0 & 0 & 0 & 0 & 0 & 0 & 0,11 & 1 & 0 & 1 & 0 & 0 & 0 & 1 & 0 & 0 & hfo \\
\hline $\begin{array}{l}\text { Meteorium nigrescens (Hedw.) Dozy } \\
\& \text { Molk. }\end{array}$ & 1 & 0 & 0 & 0 & 0 & 0 & 1 & 0 & 0 & 0 & 0 & 0 & 0 & 0 & 0 & 0 & 0 & 0 & 0,11 & 1 & 0 & 0 & 1 & 0 & 1 & 1 & 0 & 1 & ple \\
\hline Octoblepharum cocuiense Mitt. & 0 & 0 & 0 & 0 & 0 & 0 & 0 & 0 & 0 & 0 & 1 & 0 & 0 & 0 & 0 & 0 & 1 & 0 & 0,11 & 0 & 1 & 0 & 1 & 0 & 1 & 1 & 0 & 0 & acr \\
\hline Octoblepharum cylindricum Mont. & 0 & 0 & 0 & 0 & 0 & 1 & 0 & 0 & 0 & 0 & 0 & 1 & 0 & 0 & 0 & 0 & 0 & 0 & 0,11 & 0 & 0 & 1 & 1 & 1 & 1 & 1 & 0 & 0 & acr \\
\hline Plagiochila rutilans Lindenb. * & 0 & 0 & 1 & 0 & 0 & 1 & 0 & 0 & 0 & 0 & 0 & 0 & 0 & 0 & 0 & 0 & 0 & 0 & 0,11 & 0 & 0 & 1 & 1 & 0 & 1 & 1 & 0 & 0 & hfo \\
\hline Racopilum tomentosum (Hedw.) Brid. & 0 & 0 & 0 & 0 & 0 & 1 & 1 & 0 & 0 & 0 & 0 & 0 & 0 & 0 & 0 & 0 & 0 & 0 & 0,11 & 1 & 0 & 1 & 0 & 0 & 1 & 1 & 0 & 1 & ple \\
\hline Sphagnum subsecundum Nees & 0 & 0 & 0 & 0 & 0 & 0 & 0 & 0 & 0 & 0 & 0 & 0 & 0 & 0 & 0 & 1 & 1 & 0 & 0,11 & 1 & 1 & 0 & 1 & 0 & 1 & 1 & 0 & 0 & $\mathrm{sph}$ \\
\hline $\begin{array}{l}\text { Splachnobryum obtusum (Brid.) } \\
\text { Müll.Hal. }\end{array}$ & 0 & 1 & 1 & 0 & 0 & 0 & 0 & 0 & 0 & 0 & 0 & 0 & 0 & 0 & 0 & 0 & 0 & 0 & 0,11 & 0 & 1 & 1 & 1 & 0 & 1 & 1 & 0 & 1 & acr \\
\hline $\begin{array}{l}\text { Symphyogyna brasiliensis (Nees) } \\
\text { Nees \& Mont. }\end{array}$ & 0 & 0 & 0 & 0 & 1 & 0 & 0 & 1 & 0 & 0 & 0 & 0 & 0 & 0 & 0 & 0 & 0 & 0 & 0,11 & 0 & 1 & 0 & 1 & 0 & 1 & 1 & 0 & 0 & hta \\
\hline $\begin{array}{l}\text { Trachyphyllum dusenii (Müll.Hal. ex } \\
\text { Broth.) Broth. }\end{array}$ & 0 & 0 & 0 & 1 & 0 & 0 & 0 & 1 & 0 & 0 & 0 & 0 & 0 & 0 & 0 & 0 & 0 & 0 & 0,11 & 1 & 1 & 0 & 0 & 0 & 1 & 0 & 0 & 0 & ple \\
\hline $\begin{array}{l}\text { Trachyxiphium saxicola (R.S. } \\
\text { Williams) Vaz-Imbassahy \& Costa * }\end{array}$ & 0 & 1 & 0 & 0 & 0 & 0 & 0 & 1 & 0 & 0 & 0 & 0 & 0 & 0 & 0 & 0 & 0 & 0 & 0,11 & 0 & 1 & 0 & 0 & 0 & 1 & 1 & 0 & 0 & ple \\
\hline $\begin{array}{l}\text { Zelometeorium patulum (Hedw.) } \\
\text { Manuel }\end{array}$ & 0 & 1 & 0 & 0 & 0 & 0 & 1 & 0 & 0 & 0 & 0 & 0 & 0 & 0 & 0 & 0 & 0 & 0 & 0,11 & 1 & 1 & 0 & 1 & 0 & 1 & 1 & 0 & 1 & ple \\
\hline Acrolejeunea emergens (Mitt.) Steph. & 0 & 0 & 0 & 0 & 0 & 0 & 0 & 0 & 0 & 0 & 0 & 0 & 0 & 0 & 1 & 0 & 0 & 1 & 0,06 & 0 & 0 & 1 & 1 & 0 & 1 & 1 & 1 & 1 & hfo \\
\hline Calymperes afzelii Sw. & 0 & 0 & 0 & 0 & 0 & 0 & 0 & 0 & 0 & 0 & 0 & 0 & 0 & 0 & 1 & 0 & 0 & 1 & 0,06 & 0 & 0 & 1 & 1 & 0 & 1 & 1 & 0 & 0 & acr \\
\hline
\end{tabular}


Research, Society and Development, v. 10, n. 11, e272101119647, 2021

(CC BY 4.0) | ISSN 2525-3409 | DOI: http://dx.doi.org/10.33448/rsd-v10i11.19647

\begin{tabular}{|c|c|c|c|c|c|c|c|c|c|c|c|c|c|c|c|c|c|c|c|c|c|c|c|c|c|c|c|c|c|}
\hline Fissidens inaequalis Mitt. * & 0 & 1 & 0 & 0 & 0 & 0 & 0 & 0 & 0 & 0 & 0 & 0 & 0 & 0 & 0 & 0 & 0 & 1 & 0,06 & 0 & 1 & 1 & 1 & 0 & 1 & 1 & 0 & 0 & acr \\
\hline $\begin{array}{l}\text { Syrrhopodon annotinus Reese \& } \\
\text { Griff. ** }\end{array}$ & 0 & 0 & 0 & 0 & 0 & 0 & 0 & 0 & 0 & 0 & 0 & 0 & 0 & 0 & 1 & 0 & 0 & 1 & 0,06 & 0 & 0 & 1 & 1 & 0 & 0 & 0 & 0 & 0 & acr \\
\hline $\begin{array}{l}\text { Acanthocoleus aberrans (Lindenb. \& } \\
\text { Gottsche) Kruijt }\end{array}$ & 1 & 0 & 0 & 0 & 0 & 0 & 0 & 0 & 0 & 0 & 0 & 0 & 0 & 0 & 0 & 0 & 0 & 0 & 0,06 & 1 & 0 & 0 & 0 & 0 & 1 & 1 & 1 & 0 & hfo \\
\hline $\begin{array}{l}\text { Dibrachiella auberiana (Mont.) X.Q. } \\
\text { Shi, R.L. Zhu \& Gradst. * }\end{array}$ & 1 & 0 & 0 & 0 & 0 & 0 & 0 & 0 & 0 & 0 & 0 & 0 & 0 & 0 & 0 & 0 & 0 & 0 & 0,06 & 1 & 0 & 0 & 1 & 0 & 1 & 1 & 0 & 0 & hfo \\
\hline $\begin{array}{l}\text { Brachythecium ruderale (Brid.) W.R. } \\
\text { Buck }\end{array}$ & 0 & 1 & 0 & 0 & 0 & 0 & 0 & 0 & 0 & 0 & 0 & 0 & 0 & 0 & 0 & 0 & 0 & 0 & 0,06 & 0 & 1 & 0 & 0 & 0 & 0 & 1 & 0 & 1 & ple \\
\hline Bryopteris filicina (Sw.) Nees & 0 & 0 & 0 & 0 & 0 & 1 & 0 & 0 & 0 & 0 & 0 & 0 & 0 & 0 & 0 & 0 & 0 & 0 & 0,06 & 0 & 0 & 1 & 1 & 0 & 1 & 1 & 0 & 1 & hfo \\
\hline Bryum apiculatum Schwägr. & 0 & 0 & 1 & 0 & 0 & 0 & 0 & 0 & 0 & 0 & 0 & 0 & 0 & 0 & 0 & 0 & 0 & 0 & 0,06 & 0 & 0 & 1 & 0 & 1 & 1 & 1 & 0 & 0 & acr \\
\hline Bryum huillense Welw. \& Duby * & 0 & 1 & 0 & 0 & 0 & 0 & 0 & 0 & 0 & 0 & 0 & 0 & 0 & 0 & 0 & 0 & 0 & 0 & 0,06 & 0 & 1 & 0 & 1 & 0 & 0 & 1 & 0 & 0 & acr \\
\hline $\begin{array}{l}\text { Cheilolejeunea trifaria var. clausa } \\
\text { (Nees \& Mont.) Gradst. \& CJ. Bastos. }\end{array}$ & 0 & 0 & 1 & 0 & 0 & 0 & 0 & 0 & 0 & 0 & 0 & 0 & 0 & 0 & 0 & 0 & 0 & 0 & 0,06 & 0 & 0 & 1 & 1 & 0 & 1 & 1 & 0 & 0 & hfo \\
\hline Dicranella hilariana (Mont.) Mitt. * & 0 & 0 & 0 & 0 & 0 & 0 & 0 & 1 & 0 & 0 & 0 & 0 & 0 & 0 & 0 & 0 & 0 & 0 & 0,06 & 0 & 1 & 0 & 1 & 0 & 1 & 1 & 0 & 0 & acr \\
\hline Dumortiera hirsuta (Sw.) Nees & 0 & 0 & 1 & 0 & 0 & 0 & 0 & 0 & 0 & 0 & 0 & 0 & 0 & 0 & 0 & 0 & 0 & 0 & 0,06 & 0 & 0 & 1 & 1 & 1 & 0 & 1 & 0 & 1 & hta \\
\hline $\begin{array}{l}\text { Ectropothecium leptochaeton } \\
\text { (Schwägr.) W.R. Buck * }\end{array}$ & 0 & 0 & 1 & 0 & 0 & 0 & 0 & 0 & 0 & 0 & 0 & 0 & 0 & 0 & 0 & 0 & 0 & 0 & 0,06 & 0 & 0 & 1 & 1 & 0 & 1 & 1 & 0 & 1 & ple \\
\hline $\begin{array}{l}\text { Entodontopsis nitens (Mitt.) W.R. } \\
\text { Buck \& Ireland }\end{array}$ & 1 & 0 & 0 & 0 & 0 & 0 & 0 & 0 & 0 & 0 & 0 & 0 & 0 & 0 & 0 & 0 & 0 & 0 & 0,06 & 1 & 0 & 0 & 1 & 0 & 1 & 1 & 0 & 1 & ple \\
\hline
\end{tabular}


Research, Society and Development, v. 10, n. 11, e272101119647, 2021

(CC BY 4.0) | ISSN 2525-3409 | DOI: http://dx.doi.org/10.33448/rsd-v10i11.19647

\begin{tabular}{|c|c|c|c|c|c|c|c|c|c|c|c|c|c|c|c|c|c|c|c|c|c|c|c|c|c|c|c|c|c|c|}
\hline $\begin{array}{l}\text { Erythrodontium longisetum (Hook.) } \\
\text { Paris }\end{array}$ & 0 & 0 & 0 & 1 & 0 & 0 & 0 & 0 & 0 & 0 & 0 & 0 & 0 & 0 & 0 & 0 & 0 & 0 & 0,06 & 1 & 0 & 0 & 0 & 0 & 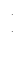 & & 1 & 0 & 1 & ple \\
\hline $\begin{array}{l}\text { Eulacophyllum cultelliforme (Sull.) } \\
\text { W.R. Buck \& Ireland * }\end{array}$ & 0 & 0 & 0 & 0 & 0 & 1 & 0 & 0 & 0 & 0 & 0 & 0 & 0 & 0 & 0 & 0 & 0 & 0 & 0,06 & 0 & 0 & 1 & 1 & 0 & 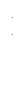 & & 1 & 0 & 1 & ple \\
\hline Fissidens angustelimbatus Mitt. & 0 & 0 & 0 & 0 & 1 & 0 & 0 & 0 & 0 & 0 & 0 & 0 & 0 & 0 & 0 & 0 & 0 & 0 & 0,06 & 0 & 1 & 0 & 1 & 1 & the & & 1 & 1 & 1 & acr \\
\hline Fissidens flaccidus Mitt. & 0 & 0 & 1 & 0 & 0 & 0 & 0 & 0 & 0 & 0 & 0 & 0 & 0 & 0 & 0 & 0 & 0 & 0 & 0,06 & 0 & 0 & 1 & 1 & 1 & & & 1 & 1 & 1 & acr \\
\hline Fissidens lagenarius Mitt. & 0 & 0 & 0 & 0 & 0 & 0 & 0 & 0 & 0 & 0 & 0 & 0 & 0 & 1 & 0 & 0 & 0 & 0 & 0,06 & 0 & 1 & 0 & 1 & 1 & 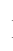 & & 1 & 0 & 1 & acr \\
\hline Fissidens zollingeri Mont. & 1 & 0 & 0 & 0 & 0 & 0 & 0 & 0 & 0 & 0 & 0 & 0 & 0 & 0 & 0 & 0 & 0 & 0 & 0,06 & 1 & 0 & 0 & 1 & 1 & 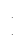 & & 1 & 0 & 1 & acr \\
\hline Frullania dusenii Steph. & 0 & 0 & 1 & 0 & 0 & 0 & 0 & 0 & 0 & 0 & 0 & 0 & 0 & 0 & 0 & 0 & 0 & 0 & 0,06 & 0 & 0 & 1 & 1 & 0 & the & & 1 & 0 & 0 & hfo \\
\hline Frullania ericoides (Nees) Mont. & 1 & 0 & 0 & 0 & 0 & 0 & 0 & 0 & 0 & 0 & 0 & 0 & 0 & 0 & 0 & 0 & 0 & 0 & 0,06 & 1 & 0 & 0 & 1 & 1 & thata & & 1 & 1 & 1 & hfo \\
\hline Frullania gibbosa Nees & 0 & 0 & 0 & 1 & 0 & 0 & 0 & 0 & 0 & 0 & 0 & 0 & 0 & 0 & 0 & 0 & 0 & 0 & 0,06 & 1 & 0 & 0 & 1 & 1 & 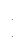 & & 1 & 0 & 1 & hfo \\
\hline $\begin{array}{l}\text { Garckea flexuosa (Griff.) Margad. \& } \\
\text { Nork. * }\end{array}$ & 0 & 0 & 0 & 0 & 0 & 0 & 0 & 1 & 0 & 0 & 0 & 0 & 0 & 0 & 0 & 0 & 0 & 0 & 0,06 & 0 & 1 & 0 & 0 & 0 & s. & & 0 & 0 & 0 & acr \\
\hline Isopterygium affusum Mitt. & 0 & 0 & 0 & 0 & 0 & 0 & 0 & 0 & 0 & 0 & 1 & 0 & 0 & 0 & 0 & 0 & 0 & 0 & 0,06 & 0 & 1 & 0 & 1 & 0 & & & 1 & 0 & 0 & ple \\
\hline Lejeunea glaucescens Gottsche & 1 & 0 & 0 & 0 & 0 & 0 & 0 & 0 & 0 & 0 & 0 & 0 & 0 & 0 & 0 & 0 & 0 & 0 & 0,06 & 1 & 0 & 0 & 1 & 0 & & & 1 & 0 & 1 & hfo \\
\hline $\begin{array}{l}\text { Leucobryum subobtusifolium (Broth.) } \\
\text { B.H. Allen }\end{array}$ & 1 & 0 & 0 & 0 & 0 & 0 & 0 & 0 & 0 & 0 & 0 & 0 & 0 & 0 & 0 & 0 & 0 & 0 & 0,06 & 1 & 0 & 0 & 1 & 0 & & & 0 & 0 & 0 & acr \\
\hline $\begin{array}{l}\text { Lopholejeunea nigricans (Lindenb.) } \\
\text { Schiffn. }\end{array}$ & 0 & 0 & 0 & 0 & 0 & 0 & 0 & 0 & 1 & 0 & 0 & 0 & 0 & 0 & 0 & 0 & 0 & 0 & 0,06 & 0 & 0 & 1 & 1 & 0 & & & 1 & 0 & 1 & hfo \\
\hline
\end{tabular}


Research, Society and Development, v. 10, n. 11, e272101119647, 2021

(CC BY 4.0) | ISSN 2525-3409 | DOI: http://dx.doi.org/10.33448/rsd-v10i11.19647

\begin{tabular}{|c|c|c|c|c|c|c|c|c|c|c|c|c|c|c|c|c|c|c|c|c|c|c|c|c|c|c|c|c|c|c|c|}
\hline $\begin{array}{l}\text { Meteorium deppei (Hornsch. ex } \\
\text { Müll.Hal.) Mitt. }\end{array}$ & 0 & 0 & 1 & 0 & 0 & 0 & 0 & 0 & 0 & 0 & 0 & 0 & 0 & 0 & 0 & 0 & 0 & 0 & 0,06 & 0 & 0 & 1 & 0 & & 0 & 1 & 1 & ( & & 1 & ple \\
\hline $\begin{array}{l}\text { Neckeropsis undulata (Hedw.) } \\
\text { Reichardt }\end{array}$ & 0 & 0 & 0 & 0 & 0 & 1 & 0 & 0 & 0 & 0 & 0 & 0 & 0 & 0 & 0 & 0 & 0 & 0 & 0,06 & 0 & 0 & 1 & 1 & & 1 & 1 & 1 & 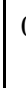 & & 1 & ple \\
\hline $\begin{array}{l}\text { Neesioscyphus argillaceus (Nees) } \\
\text { Grolle }\end{array}$ & 0 & 0 & 0 & 0 & 0 & 0 & 0 & 1 & 0 & 0 & 0 & 0 & 0 & 0 & 0 & 0 & 0 & 0 & 0,06 & 0 & 1 & 0 & 0 & & 0 & 1 & 1 & 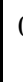 & & 0 & hfo \\
\hline Pelekium involvens (Hedw.) Touw & 0 & 0 & 1 & 0 & 0 & 0 & 0 & 0 & 0 & 0 & 0 & 0 & 0 & 0 & 0 & 0 & 0 & 0 & 0,06 & 0 & 0 & 1 & 1 & & 0 & 1 & 1 & 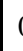 & & 1 & ple \\
\hline $\begin{array}{l}\text { Philonotis hastata (Duby) Wijk \& } \\
\text { Margad. }\end{array}$ & 0 & 0 & 0 & 0 & 1 & 0 & 0 & 0 & 0 & 0 & 0 & 0 & 0 & 0 & 0 & 0 & 0 & 0 & 0,06 & 0 & 1 & 0 & 1 & & 1 & 1 & 1 & & & 1 & acr \\
\hline Pireella pohlii (Schwägr.) Cardot & 0 & 0 & 0 & 0 & 0 & 1 & 0 & 0 & 0 & 0 & 0 & 0 & 0 & 0 & 0 & 0 & 0 & 0 & 0,06 & 0 & 0 & 1 & 1 & & 0 & 1 & 1 & 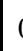 & & 0 & ple \\
\hline Plagiochila montagnei Nees * & 0 & 0 & 0 & 0 & 0 & 1 & 0 & 0 & 0 & 0 & 0 & 0 & 0 & 0 & 0 & 0 & 0 & 0 & 0,06 & 0 & 0 & 1 & 1 & & 0 & 0 & 1 & ( & & 0 & hfo \\
\hline Plagiochila patula (Sw.) Lindenb. * & 0 & 0 & 1 & 0 & 0 & 0 & 0 & 0 & 0 & 0 & 0 & 0 & 0 & 0 & 0 & 0 & 0 & 0 & 0,06 & 0 & 0 & 1 & 0 & & 0 & 0 & 1 & ( & & 0 & hfo \\
\hline Rhodobryum roseum (Hedw.) Limpr. & 0 & 0 & 0 & 0 & 0 & 1 & 0 & 0 & 0 & 0 & 0 & 0 & 0 & 0 & 0 & 0 & 0 & 0 & 0,06 & 0 & 0 & 1 & 0 & & 0 & 0 & 1 & 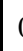 & & 0 & acr \\
\hline $\begin{array}{l}\text { Rhynchostegium conchophyllum } \\
\text { A.Jaeger }\end{array}$ & 1 & 0 & 0 & 0 & 0 & 0 & 0 & 0 & 0 & 0 & 0 & 0 & 0 & 0 & 0 & 0 & 0 & 0 & 0,06 & 1 & 0 & 0 & 0 & & 0 & 1 & 1 & 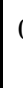 & & 0 & ple \\
\hline $\begin{array}{l}\text { Sematophyllum adnatum (Michx.) } \\
\text { Brid. }\end{array}$ & 0 & 0 & 0 & 0 & 0 & 0 & 0 & 0 & 0 & 0 & 0 & 0 & 1 & 0 & 0 & 0 & 0 & 0 & 0,06 & 1 & 0 & 0 & 0 & & 0 & 1 & 1 & 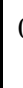 & & 0 & ple \\
\hline Syrrhopodon ligulatus Mont. & 0 & 0 & 0 & 0 & 0 & 0 & 0 & 0 & 0 & 0 & 1 & 0 & 0 & 0 & 0 & 0 & 0 & 0 & 0,06 & 0 & 1 & 0 & 1 & & 0 & 1 & 1 & ( & & 0 & acr \\
\hline Syrrhopodon tortilis Hampe ** & 0 & 0 & 0 & 0 & 0 & 0 & 0 & 0 & 0 & 0 & 0 & 0 & 0 & 1 & 0 & 0 & 0 & 0 & 0,06 & 0 & 1 & 0 & 0 & & 0 & 0 & 1 & 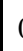 & & 0 & acr \\
\hline $\begin{array}{l}\text { Thuidium delicatulum (Hedw.) Bruch } \\
\text { \& Schimp. }\end{array}$ & 0 & 0 & 0 & 0 & 0 & 1 & 0 & 0 & 0 & 0 & 0 & 0 & 0 & 0 & 0 & 0 & 0 & 0 & 0,06 & 0 & 0 & 1 & 1 & & 0 & 1 & 1 & 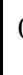 & & 0 & ple \\
\hline
\end{tabular}


Research, Society and Development, v. 10, n. 11, e272101119647, 2021

(CC BY 4.0) | ISSN 2525-3409 | DOI: http://dx.doi.org/10.33448/rsd-v10i11.19647

\begin{tabular}{|c|c|c|c|c|c|c|c|c|c|c|c|c|c|c|c|c|c|c|c|c|c|c|c|c|c|c|c|c|c|}
\hline $\begin{array}{l}\text { Trichosteleum subdemissum (Besch.) } \\
\text { A.Jaeger }\end{array}$ & 0 & 0 & 0 & 0 & 0 & 0 & 0 & 0 & 0 & 0 & 0 & 0 & 0 & 0 & 1 & 0 & 0 & 0 & 0,06 & 0 & 0 & 1 & 1 & 0 & 1 & 1 & 0 & 0 & acr \\
\hline Bryum coronatum Schwägr. & 0 & 0 & 0 & 0 & 0 & 0 & 0 & 0 & 0 & 0 & 0 & 0 & 0 & 0 & 0 & 0 & 0 & 1 & 0,00 & 0 & 0 & 1 & 1 & 1 & 1 & 1 & 1 & 1 & acr \\
\hline Fissidens pellucidus Hornsch. & 0 & 0 & 0 & 0 & 0 & 0 & 0 & 0 & 0 & 0 & 0 & 0 & 0 & 0 & 0 & 0 & 0 & 1 & 0,00 & 0 & 0 & 1 & 1 & 1 & 1 & 1 & 1 & 1 & acr \\
\hline Leucoloma tortellum (Mitt.) A.Jaeger & 0 & 0 & 0 & 0 & 0 & 0 & 0 & 0 & 0 & 0 & 0 & 0 & 0 & 0 & 0 & 0 & 0 & 1 & 0,00 & 0 & 0 & 1 & 1 & 0 & 1 & 1 & 0 & 0 & acr \\
\hline Total & 26 & 17 & 28 & 14 & 14 & 24 & 8 & 17 & 14 & 8 & 10 & 13 & 6 & 11 & 18 & 1 & 6 & 25 & 13,78 & 48 & 48 & 69 & 74 & 27 & 87 & 97 & 17 & 48 & \\
\hline
\end{tabular}

Fonte: Autores. 
Figura 2. Riqueza de espécies de briófitas por família coletada no município de Mineiros estado de Goiás (MIGO) e no município de Nova Xavantina estado do Mato Grosso (NOMT). Siglas: Outr: famílias que possuíam menos de três espécies; Leje: Lejeuneaceae; Fiss Fissidentaceae; Sema: Sematophyllaceae; Caly: Calymperaceae; Hypn: Hypnaceae; Brya: Bryaceae; Leuc: Leucobryaceae; Plag: Plagiochilaceae; Pott: Pottiaceae; Ptero: Pterobryaceae; Thui: Thuidiaceae; Bart: Bartramiaceae; Frul: Frullaniaceae; Lepi: Lepidoziaceae e Pall: Pallaviciniaceae.

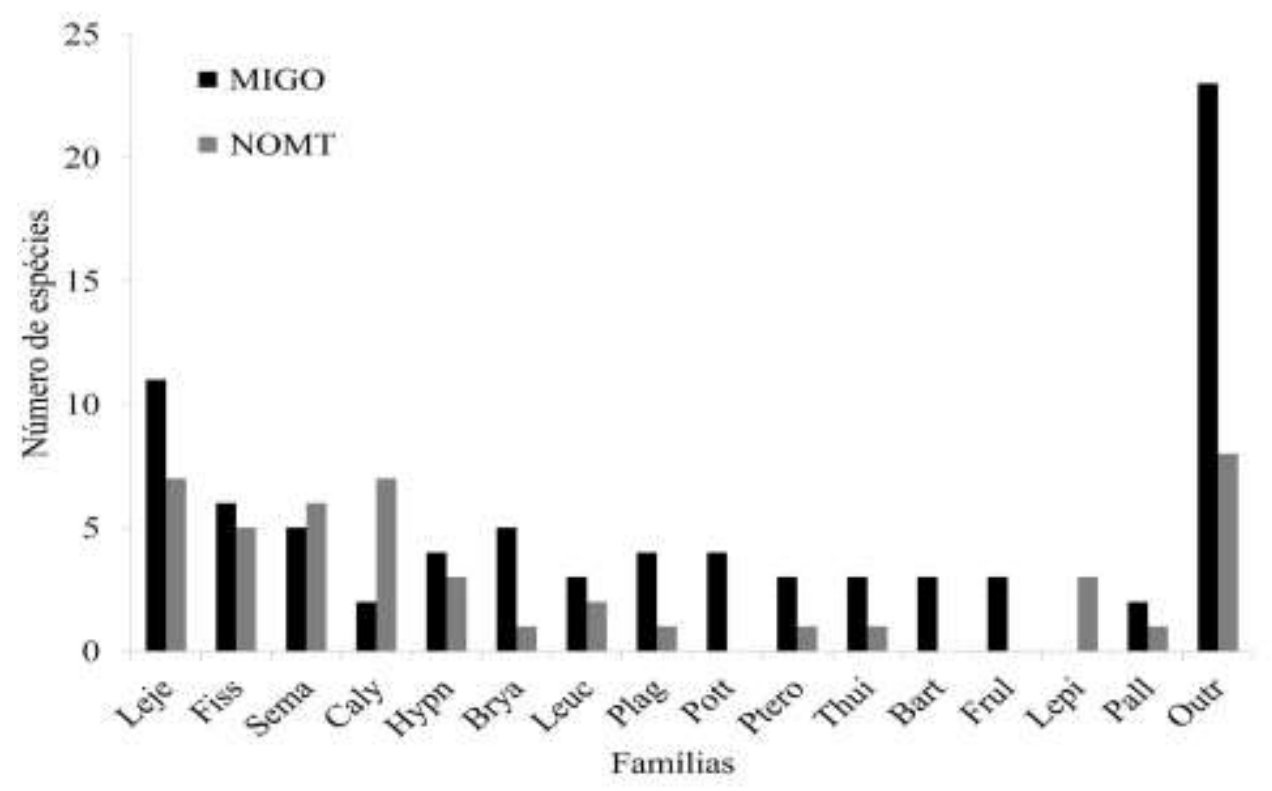

Fonte: Autores.

Após verificar a literatura e principalmente Flora do Brasil (2020), 18 espécies encontradas são novos registros para o estado de Goiás (Quadro 2, marcados com “*”) e 7 são novos registros para o estado de Mato Grosso (Quadro 2, marcados com “**”). Este número de novos registros de briófitas para os dois estados mostra a carência de estudos nesta região e que ambientes associados a cachoeiras devem ser mais explorados.

Lejeuneaceae é sempre a família de briófitas mais rica em florestas tropicais baixas (Gradstein 1995). No bioma Cerrado Genevro et al. (2006), estudando mata de galeria no estado de Mato Grosso, apontou Lejeuneaceae como representando $24 \%$ do total de espécies encontradas; no checklist das espécies do Distrito Federal (Câmara et al. 2005) essa família representou 10\% das espécies registradas; e também foi a família mais representativa (34\%) no estudo de Câmara e Vital (2004), no Pantanal de Mato Grosso; e (21\%) Peralta e Yano (2005), em uma floresta pantanosa no estado de São Paulo.

Flora do Brasil (2020) cita para a região Centro-Oeste 511 espécies de briófitas, neste estudo registrou-se 21\% (102) destas, 28\% de Goiás (96 de 340 espécies) e 15\% de Mato Grosso (47 de 311 espécies). A área estudada é pequena em relação aos estados e do Centro-Oeste como um todo, porém apresenta alta representatividade da flora regional, o que nos remete ao fato da disponibilidade dessas áreas e assim manutenção da flora. Assim, existe a importância imediata da conservação dessas áreas, porque devido à sua beleza chama a atenção de visitantes que muitas vezes não se preocupam com as briófitas, causando modificações em ambientes colonizados e a consequente perda da diversidade.

A maior riqueza de briófitas encontrada em Mineiros pode ser explicada pelo tipo de vegetação que ocorre a montante das cachoeiras estudadas, pois enquanto nas três cachoeiras do município, o tipo de vegetação é formado por mata ciliar e, nas três cachoeiras localizadas em Nova Xavantina, a vegetação é formado por "vereda", pequenas manchas de "cerrado rupestre", pastagem úmida, e alguns trechos com vegetação lenhosa e buritis. A vegetação com maior número de substratos para 
colonização (troncos de árvores por exemplo) amplia a ocorrência de espécies de briófitas.

Os ambientes "Vereda" possuem menos variedade de substratos, maior incidência de luz e, portanto, maior temperatura. No entanto, a falta de estudos sobre briófitas no bioma para esse tipo de vegetação não nos permite fazer comparações com a listagem de espécies aqui encontradas.

A cachoeira Luzimar possui maior riqueza em relação às demais. Essa diferença pode estar relacionada ao perfil do riacho e da mata ciliar de cada cachoeira. Observando imagens de satélite dos ambientes analisados, as matas ciliares associadas ao riacho Cachoeira Luzimar são mais densas e, além disso, o riacho a montante da cachoeira é mais estreito com dossel da mata ciliar e cerrado. Esses fatores contribuem para uma menor incidência de luz no interior da floresta, que segundo Genevro et al. (2006), favorecendo a estabilidade do meio ambiente e desta forma o estabelecimento de espécies de briófitas.

Em relação ao trabalho das briófitas em cachoeira é conhecido apenas por Djan-Chekar (1993), que realizou um estudo sobre briófitas com uma cachoeira na província de British Columbia, Canadá. Por ser um trabalho de características ambientais distintas ao deste estudo, pois ocorreu em uma cachoeira de ambiente temperado e, não apresentou espécies em comum Devido à escassez de estudos em cachoeiras de briófitas, não foi possível realizar mais comparações com outros trabalhos, refletindo a necessidade de mais estudos nestes ambientes.

O agrupamento de similaridade florística entre os ambientes preferenciais de ocorrência (Figura 3) não apresentou ordenação, porém quando a ordenação levou em consideração as cachoeiras (Figura 4), aquelas localizadas em Mato Grosso são mais similares entre si.

Figura 3. Dendrograma de similaridade florística entre os ambientes das briófitas de todas as cachoeiras estudadas no município de Mineiros, estado de Goiás (MIGO - quadrado preto) e Nova Xavantina, estado do Mato Grosso (NOMT - quadrado cinza). Siglas: ju - jusante, qu - queda e mo) montante, Ad - Adão, Ch - Chupador, Bo - Botina, Su - Sucuri, Pi - Pinguela e Lu - Luzimar.

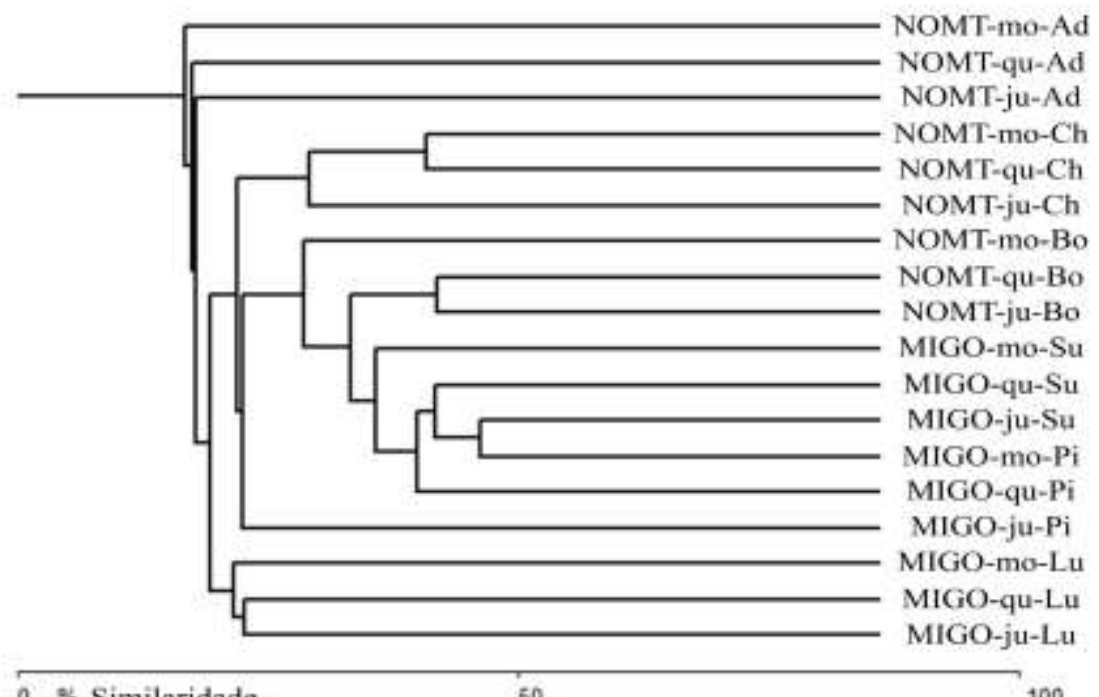

Fonte: Autores. 
Figura 4. Dendrograma de similaridade florística entre briófitas das cachoeiras dos municípios de Mineiros estado de Goiás (MIGO) e Nova Xavantina estado de Mato Grosso (NOMT). Siglas: Ad - Adão, Ch - Chupador, Bb - Ribeirão Botina, Su Sucuri, Pi - Pinguela e Lu - Luzimar.

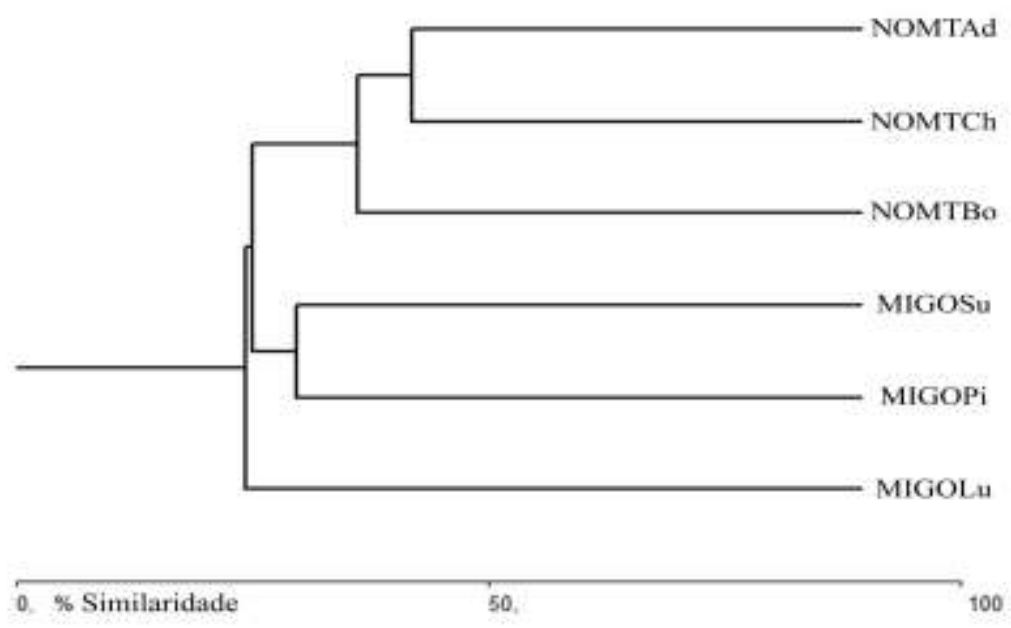

Fonte: Autores.

As espécies mais frequentes neste estudo (consideradas aqui como aquelas que possuíam frequência maior ou igual 40 \%) foram Riccardia cataractarum, Jaegerina scariosa e Microcalpe subsimplex (Quadro 2), as duas últimas espécies são comuns em levantamentos de Cerrado e são citadas na maioria dos levantamentos (Valente et al. 2013, Souza \& Câmara 2015, Carmo \& Peralta 2016), porém a maior frequência de Riccardia cataractarum está ligada a ocorrência das cachoeiras pois é uma hepática talosa que possui morfologia simples estritamente ligada a ambientes de alta disponibilidade de água.

A distribuição nos ambientes de ocorrência, mostra que a montante (mo) possui 47 espécies, queda (qu) 48 espécies e jusante (ju) 70 espécies. Porém a maior parte das espécies (43) teve menos de 10\% de frequência, e foram consideradas raras, sendo que mo possui 13 espécies exclusivas, que possui 14 e a ju possui 30 espécies exclusivas (Quadro 2). A distribuição das espécies raras mostra que a comunidade claramente se modificou ao longo das áreas amostradas nas cachoeiras e que a existência de uma cachoeira possui capacidade de sustentar espécies exclusivas desse ambiente.

A distribuição da listagem florística nos Biomas brasileiros mostra que a listagem geral (Quadro 3) apresenta maior ocorrência de espécies em comum com a Mata Atlântica (MA), seguido de Cerrado (CE) e Amazônia (AM), porém quando analisamos a distribuição das espécies de acordo com os estados as espécies das cachoeiras de Goiás são mais semelhantes às aquelas ocorrentes no Bioma Pantanal (PA) (Quadro 4), quando aquelas ocorrentes em Mato Grosso estão mais relacionadas às da Amazônia (Quadro 5). 
Quadro 3. Comparação da ocorrência de todas as espécies encontradas nos Biomas brasileiros. Siglas: AM - Amazônia, CA Caatinga, CE - Cerrado, MA - Mata Atlântica, PA - Pampa, PT - Pantanal.

\begin{tabular}{|l|c|c|c|c|c|c|}
\hline & Este & MA & CE & AM & PT & CA \\
\hline MA & 97 & - & - & - & - & - \\
\hline CE & 86 & 84 & - & - & - & - \\
\hline AM & 74 & 71 & 67 & - & - & - \\
\hline PT & 48 & 48 & 46 & 40 & - & - \\
\hline CA & 27 & 27 & 26 & 24 & 21 & - \\
\hline PA & 17 & 17 & 17 & 16 & 15 & 12 \\
\hline
\end{tabular}

Fonte: Autores.

Quadro 4. Comparação da ocorrência das espécies encontradas no município de Mineiros (MIGO) nos Biomas brasileiros. Siglas: AM - Amazônia, CA - Caatinga, CE - Cerrado, MA - Mata Atlântica, PA - Pampa, PT - Pantanal.

\begin{tabular}{|l|c|c|c|c|c|c|}
\hline & MIGO & MA & CE & PT & AM & CA \\
\hline MA & 76 & - & - & - & - & - \\
\hline CE & 70 & 67 & - & - & - & - \\
\hline PT & 42 & 42 & 40 & - & - & - \\
\hline AM & 55 & 53 & 51 & 34 & - & - \\
\hline CA & 22 & 22 & 21 & 17 & 19 & - \\
\hline PA & 13 & 13 & 13 & 11 & 12 & 9 \\
\hline
\end{tabular}

Fonte: Autores.

Quadro 5. Comparação da ocorrência das espécies encontradas no município de Nova Xavantina (NOMT) nos Biomas brasileiros. Siglas: AM - Amazônia, CA - Caatinga, CE - Cerrado, MA - Mata Atlântica, PA - Pampa, PT - Pantanal.

\begin{tabular}{|l|c|c|c|c|c|c|}
\hline & NOMT & MA & CE & AM & PT & CA \\
\hline MA & 42 & - & - & - & - & - \\
\hline CE & 37 & 37 & - & - & - & - \\
\hline AM & 36 & 34 & 32 & - & - & - \\
\hline PT & 19 & 19 & 19 & 17 & - & - \\
\hline CA & 14 & 14 & 14 & 13 & 12 & - \\
\hline PA & 10 & 10 & 10 & 10 & 9 & 7 \\
\hline
\end{tabular}

Fonte: Autores.

A distribuição das formas de vida das espécies entre os ambientes de ocorrência (Quadro 6) mostra que os musgos acrocárpicos e as hepáticas talosas aumentaram gradativamente o número, essas plantas são comumente relacionadas com 
ambientes estáveis e com alta umidade como margens de riachos, florestas pluviais ou nebulares. Enquanto que os musgos pleurocárpicos e hepáticas folhosas apresentou leve diminuição na queda e aumentou na jusante, essas plantas são comumente relacionadas a ambientes instáveis e apresentam inúmeras adaptações a perda de água. E somente o Sphagnum não aumentou na jusante um resultado inesperado uma vez que ele também é comumente relacionado com ambientes úmidos ou encharcados.

Quadro 6. Distribuição das espécies encontradas segundo as formas de vida. Siglas: acr - Acrocárpico, ple - pleurocárpico, hta - hepática talosa, hfo - hepática folhosa, sph - Sphagnum.

\begin{tabular}{|c|c|c|c|c|c|c|}
\hline $\begin{array}{l}\text { Formas de } \\
\text { vida }\end{array}$ & acr & ple & hfo & hta & sph & Total geral \\
\hline mo & 12 & 17 & 14 & 3 & 1 & 47 \\
\hline $\mathrm{qu}$ & 20 & 13 & 9 & 5 & 1 & 48 \\
\hline ju & 23 & 21 & 22 & 4 & 0 & 70 \\
\hline total & 36 & 31 & 28 & 6 & 1 & 102 \\
\hline
\end{tabular}

Fonte: Autores.

\section{Considerações Finais}

Nossos resultados mostram que as cachoeiras modificam os ambientes relacionados com o aumento na riqueza e composição de espécies, e mudam a comunidade em relação às formas de vida das espécies colonizadoras. As cachoeiras dos dois municípios apresentaram diferenças florísticas, pois as espécies encontradas nas cachoeiras de Nova Xavantina-MT apresentaram influência do bioma amazônico, enquanto aquelas cachoeiras do município de Mineiros-GO, com o Bioma Pantanal. Incentivamos a continuidade dos estudos de briófitas em ambientes de cachoeira porque estes vegetais dependem da água para a continuidade de seu ciclo de vida.

\section{Referências}

Aquino, F. G. \& Aguiar, L. M. S. (2007). Caracterização e Conservação da Biodiversidade do Bioma Cerrado. pp. 27-32. In: Faleiro, F. G. \& Sousa, E. S. Pesquisa, desenvolvimento e inovação para o Cerrado. Embrapa Cerrados.

Austrheim, G., Hassel, K. \& Mysterud, A. (2005). The role of life history traits for Bryophyte community patterns in two contrasting Alpine regions. The Bryologist, 108, 259-271.

Brito, A. E. R. M. \& Pôrto, K. C. (2000). Guia de estudos de briófitas: briófitas do Ceará. Fortaleza. Editora da Universidade Federal do Ceará.

Câmara, P. E. A. S. \& Costa, D. P. (2006). Hepáticas e antóceros das matas de galeria da Reserva Ecológica do IBGE, RECORD, Distrito Federal, Brasil. Hoehnea, 33, 79-87.

Câmara, P. E. A. S. \& Soares, A. E. R. (2010). A new and updated bryophyte checklist for Distrito Federal (Brasília, Brazil). Tropical Bryology, 31, 165-168.

Câmara, P. E. A. S. \& Vital, D. M. (2004). Briófitas do Município de Poconé, Pantanal de Mato Grosso, MT, Brasil. Acta Botanica Brasilica, 18, 881-886.

Câmara, P. E. A. S. (2008). Musgos pleurocárpicos das matas de galeria da Reserva Ecológica do IBGE, RECOR, Distrito Federal, Brasil. Acta Botanica Brasilica, 22, 573-581.

Câmara, P. E. A. S., Oliveira, J. R. P. M. \& Santiago, M. M. M. (2005). A Checklist of the bryophytes of Distrito Federal (Brasília, Brazil). Tropical Bryology, $26,133-140$.

Câmara, P. E. A. S., Teixeira, R., Lima, J. \& Lima, J. (2003). Musgos urbanos do Recanto das Emas, Distrito Federal, Brasil. Acta Botanica Brasilica, 17, 507513.

Carmo, D. M. do \& Peralta, D. F. (2016). Survey of bryophytes in Serra da Canastra National Park, Minas Gerais, Brazil. Acta Botanica Brasilica, 30(2), 254265.

Crandall-Stotler, B., Stotler, R. E. \& Long, D. G. (2009). Morphology and classification of the Marchantiophyta. pp. 1-54. In: Goffinet, B. \& Shaw, A. J., Bryophyte Biology. 2.ed. Cambridge University Press. 
Djan-Chekar, N. (1993). The bryophyte flora of Bridal Falls, British Columbia: an analysis of its composition and diversity. M.Sc. thesis, Department of Botany, University of British Columbia.

Durigan, G. (2003). Métodos para análise de vegetação arbórea. pp. 455-479. In: Cullen Jr., L., Rudran R. \& Valladares-Pádua C. (orgs.). Métodos de estudo em biologia da conservação e manejo da vida silvestre. Editora UFPR / Fundação O Boticário.

Flora do Brasil 2020 (2020). Jardim Botânico do Rio de Janeiro. < http://floradobrasil.jbrj.gov.br/ >.

Frahm, J. P. (2003). Manual of tropical bryology. Tropical Bryology, 23, 1-195.

Genevro, J. A., Athayde Filho, F. P. \& Peralta, D. F. (2006). Briófitas de mata de galeria no Parque Municipal Mário Viana, Nova Xavantina, Mato Grosso, Brasil. Boletim do Instituto de Botânica, 18, 149-157.

Goffinet, B., Buck, W. R. \& Shaw, A. J. (2009). Morphology, anatomy, and classification of the Bryophyta. pp. 55-138. In: Goffinet, B. \& Shaw, A. J. Bryophyte Biology. (2a ed.). Cambridge University Press.

Gradstein, S. R. (1995). Bryophyte diversity of the tropical rainforest. Archives des Sciences, 48, 91-96.

Holmgren, P. K., Holmgren, N. H. \& Barnett, L. (1990). Index herbariorum. Part 1: The herbaria of the world. 8 ed. New York Botanical Garden Press, New York.

Lima, J. E. F. W. \& Silva, E. M. (2008). Recursos Hídricos do Bioma Cerrado. Importância e situação. pp. 89-106. In: Sano, S. M., Almeida, S. P. \& Ribeiro, J.

F. (eds). Cerrado: Ecologia e Flora. Brasília, Editora da Embrapa Cerrados.

Oliveira Filho, A. T. \& Martins, F. R. (1986). Distribuição, caracterização e composição florística das formações vegetais da região da Salgadeira, na Chapada dos Guimarães (MT). Revista Brasileira de Botânica, 9, 207-223.

Oliveira, J. R. P. M., Alvarenga, L. D. P. \& Pôrto, K. C. (2006). Briófitas da Estação Ecológica de Águas Emendadas, Distrito Federal, material coletado por Daniel Moreira Vital. Boletim do Instituto de Botânica, 18, 181-195.

Peralta, D. F. \& Yano, O. (2005). Briófitas de mata paludosa, município de Zacarias, noroeste do Estado de São Paulo, Brasil. Acta Botanica Brasilica, 19(4), 963-977.

Pinto, J. R. R. \& Oliveira-Filho, A. T. (1999). Perfil florístico e estrutura da comunidade arbórea de uma floresta de vale no Parque Nacional da Chapada dos Guimarães, Mato Grosso, Brasil. Revista Brasileira de Botânica, 22, 53-67.

Ribeiro, J. F. \& Walter, B. M. T. (2008). As principais fitofisionomias do Bioma Cerrado. pp. 151-212. In: Sano, S. M., Almeida, S. P. \& Ribeiro, J. F. (eds). Cerrado: Ecologia e Flora. Brasília, Editora da Embrapa Cerrados.

Ribeiro, J. F., Fonseca, C. E. L. \& Sousa-Silva, J. C. (2001). Cerrado: caracterização e recuperação de matas de galeria. Planaltina. Editora da Embrapa Cerrados, $889 \mathrm{p}$.

Silva, F. A. M., Assad, E. D. \& Evangelista, B. A. (2008). Caracterização climática do Bioma Cerrado. p.p. 69-88. In: Sano, S.M., Almeida, S.P. \& Ribeiro, J.F. (eds). Cerrado: ecologia e flora, Editora da Embrapa Cerrado.

Souza, R. V. \& Câmara, P. E. A. S. (2015). Survey of the bryophytes of a gallery forest in the National Park of Serra do Cipó, Minas Gerais, Brazil. Acta Botanica Brasilica, 29, 24-29.

Sousa, M. A. R., Gomes-Klein, V. L. \& Yano, O. (2010). Musgos (Bryophyta) do Parque Estadual da Serra dos Pireneus, Goiás, Brasil. Revista de Biologia Neotropical, 7, 7-26.

W3TROPICOS. Missouri Botanical Garden. <http://www.tropicos.org>.

Valente, E. de B., Pôrto, K. C., Bastos. C. J. P. \& Ballejos-Loyola, J. (2013). Diversity and distribution of the bryophyte flora in montane forests in the Chapada Diamantina region of Brazil. Acta Botanica Brasilica, 27 (3), 506-518.

Yano, O. \& Bastos, C. J. P. (2004). Adições à flora de briófitas de Mato Grosso do Sul, Brasil. Acta Botanica Brasilica, 18, 437-458.

Yano, O. (1984). Contribuição ao inventário dos Musci brasileiros, 3: Racopilaceae (Bryopsida, Isobryales). Revista Brasileira Botânica, 7, 57-63. 